\title{
Surgical Enucleation of a Dentigerous Cyst in a 12-Year-Old Child: A Case Report
}

\author{
Sweta Jha, ${ }^{1}$ Bandana Koirala, ${ }^{2}$ Mamta Dali, ${ }^{3}$ Sneha Shrestha, ${ }^{4}$ Kabiraj Poudel, ${ }^{1}$ Shashi Keshwar \\ ${ }^{1}$ Post-graduate Resident, ${ }^{2}$ Professor, ${ }^{3}$ Associate Professor, ${ }^{4,5}$ Assistant Professor \\ ${ }^{1-4}$ Department of Pedodontics and Preventive Dentistry, ${ }^{5}$ Department of Oral Pathology, \\ College of Dental Surgery, B.P. Koirala Institute of Health Sciences, Dharan, Nepal
}

\begin{abstract}
Dentigerous cysts are the benign odontogenic cysts that surround the crown of an unerupted or impacted tooth and they account for approximately $20-24 \%$ of the jaw cysts. Dentigerous cysts involving impacted second premolars are rare. Here we report a case of surgical enucleation of an inflammatory type of dentigerous cyst associated with the impacted mandibular second premolar in a 12-year-old child. Nine-months follow up showed satisfactory healing of the defect with remarkable bone formation.
\end{abstract}

Keywords: Dentigerous cyst, enucleation, impacted teeth, unerupted teeth.

\section{INTRODUCTION}

Dentigerous cyst, the second most common odontogenic cyst after radicular cyst, accounts for approximately 20$24 \%$ of the jaw cysts. ${ }^{1}$ They surround the crown of either unerupted, impacted, embedded or developing teeth and are found most frequently associated with mandibular third molars, followed by maxillary canines, maxillary third molars and, rarely, the maxillary central incisors. ${ }^{2}$ They are mostly found in second to fourth decades of life with males being more commonly affected than females. ${ }^{3}$ Expansion of the follicle by collection of fluid between reduced enamel epithelium and enamel surface of an impacted tooth leads to the formation of dentigerous cyst. ${ }^{1}$ Rarely, it develops around the crown of the developing permanent tooth bud because of the intrafollicular spread of the periapical inflammation from an overlying deciduous tooth. ${ }^{4}$ Usually, it is asymptomatic unless secondarily infected and are, often detected during routine radiographic examination. ${ }^{5}$ Radiological findings

\section{Correspondence}

Dr. Sweta Jha

Post Graduate Student, Department of Pedodontics and Preventive Dentistry, BPKIHS, Dharan, Nepal

Email: swetawithyou486@gmail.com

\section{Citation}

Jha S, Koirala B, Dali M, Shrestha S, Poudel K, Keshwar S. Surgical Enucleation of a Dentigerous Cyst in a 12-Year-Old Child: A Case Report. J Nepalese Assoc Pediatr Dent. 2020;1(1):13-6. include a well-defined unilocular radiolucency associated with the crown of the unerupted tooth. The margins may be ill-defined in case of infection. It might be difficult to distinguish a dentigerous cyst from a normal tooth follicle. If the follicular space is more than $4 \mathrm{~mm}$, dentigerous cyst can be suspected. ${ }^{6}$ The possible complications that may arise from dentigerous cyst include pathologic bone fracture, bone expansion and destruction, loss of permanent teeth, development of ameloblastoma, squamous cell carcinoma and mucoepidermoid carcinoma. ${ }^{4}$ The various treatment modalities for dentigerous cyst include total enucleation, marsupialization and decompression of the cyst via fenestration. ${ }^{3}$

\section{CASE REPORT}

A 12-year-old male reported to the department of Pedodontics and Preventive Dentistry, BPKIHS, Dharan with the chief complain of swelling in the left lower back teeth region of mouth since two months. No other abnormalities were detected on general and extraoral examination.

On intraoral examination, there was presence of root stump of mandibular left deciduous second molar (75) with swelling along the vestibule from mesial aspect of deciduous mandibular first molar (74) to mesial aspect of permanent first molar (36). The swelling was firm and non-tender on palpation with expansion of the buccal cortical plate and intact lingual cortical plate (Figure 1,2). 


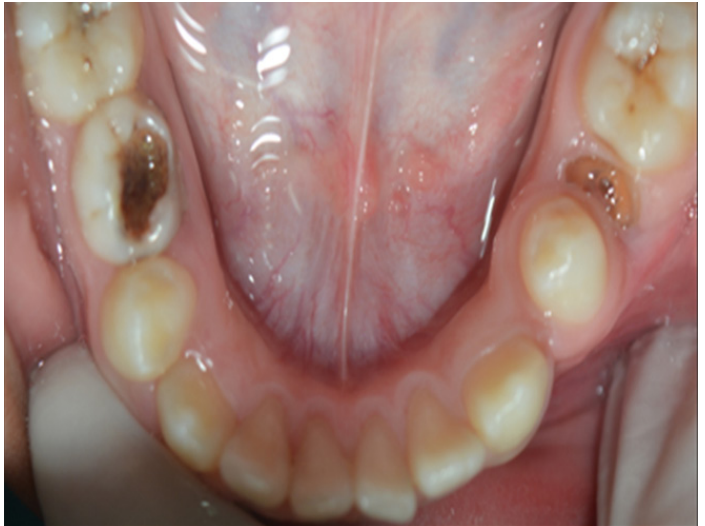

Figure 1. Preoperative - Root stump (75) with swelling.

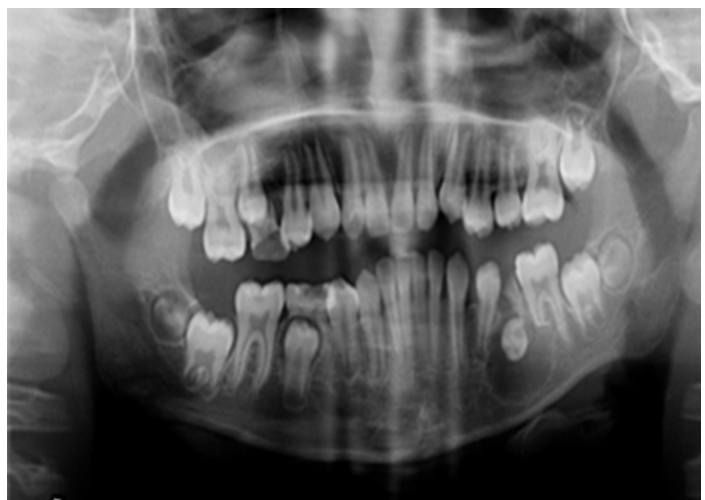

Figure 3. OPG showing horizontally impacted 35 .

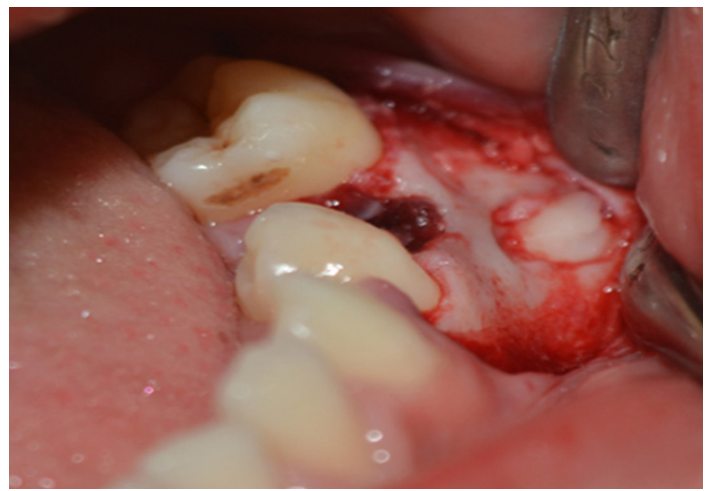

Figure 5. Exposure of impacted premolar.

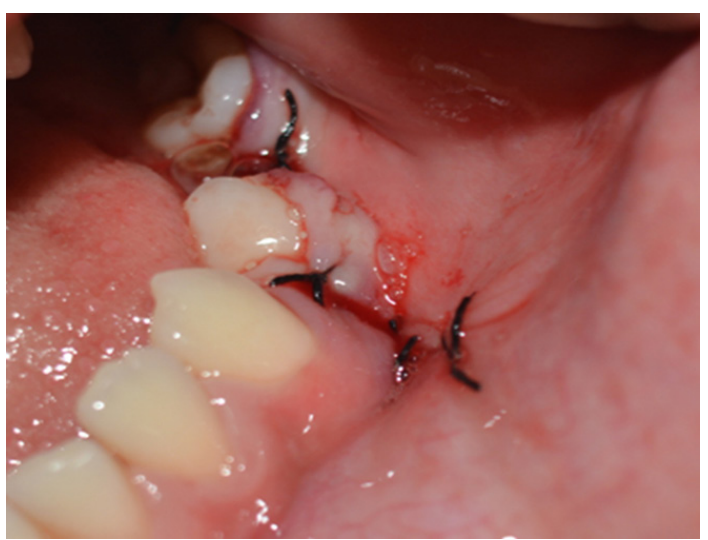

Figure 7. Surgical closure of flap.

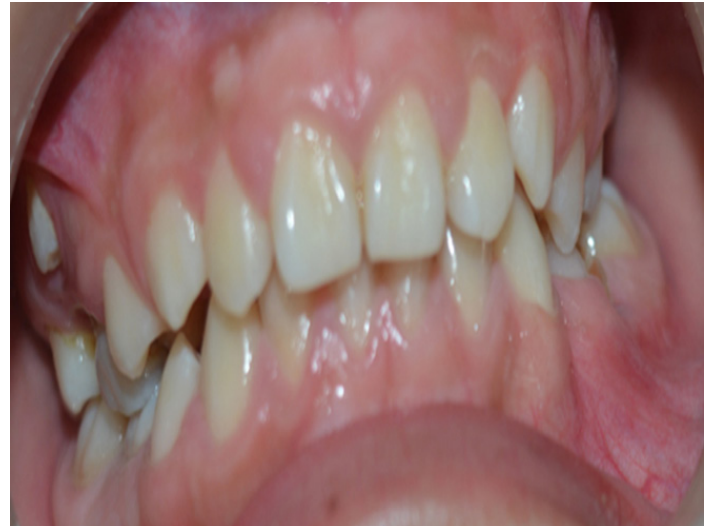

Figure 2. Preoperative - Expansion of buccal cortical plate $(74,75)$.

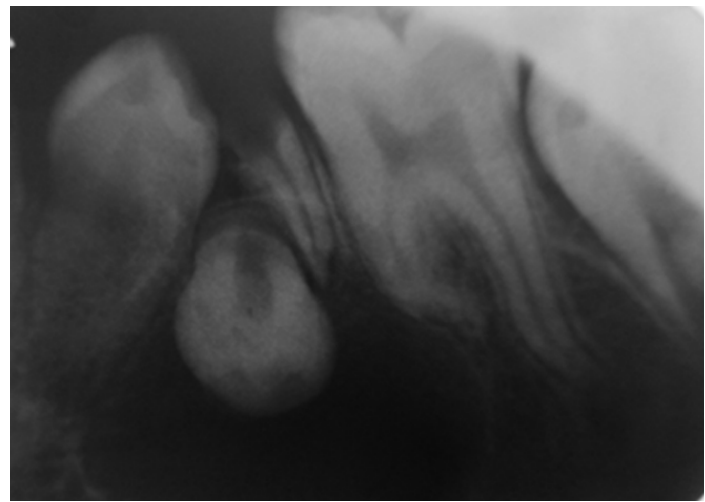

Figure 4. IOPA showing dilaceration of mesial root of 36 .

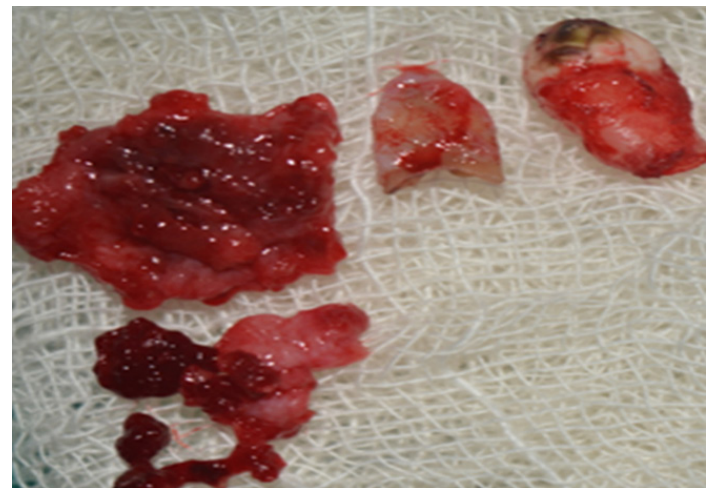

Figure 6. Enucleated cystic mass and extracted 75 and 35.

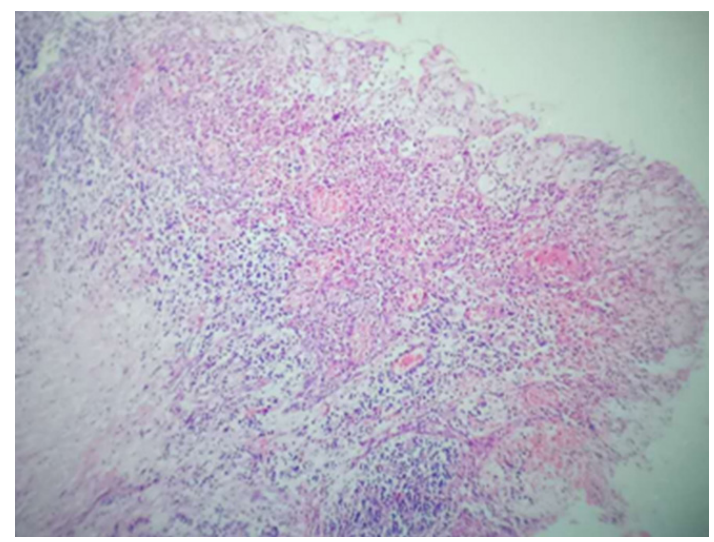

Figure 8. Histopathological at $10 \mathrm{X}$ magnification. 


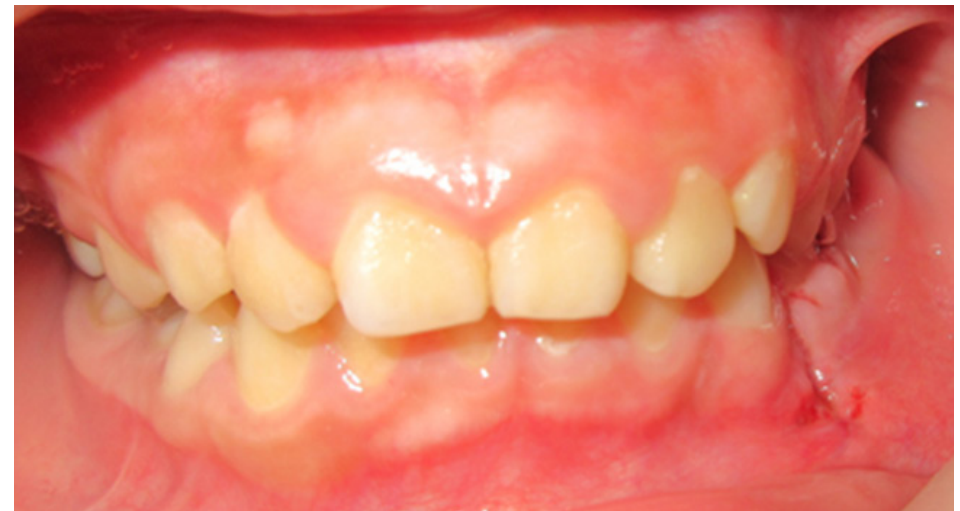

Figure 9. One week postoperative follow up.

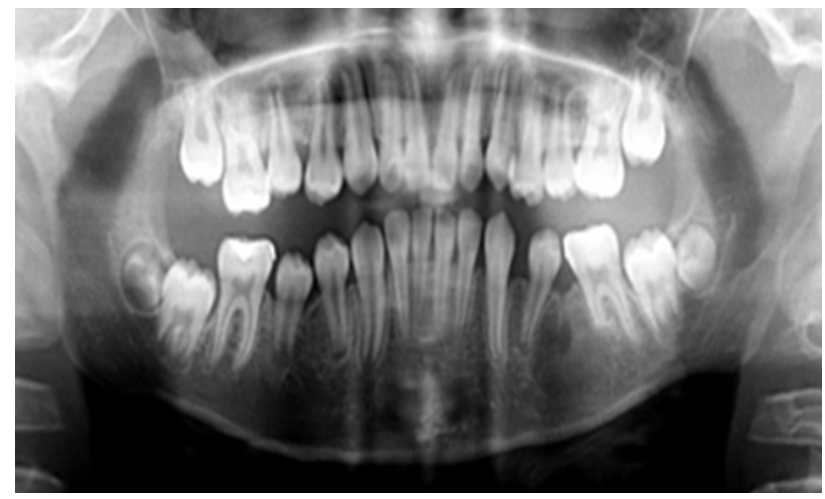

Figure 11. OPG after three months.

Orthopantomogram (OPG) revealed a well-defined unilocular radiolucency extending from the apical third of root of 75, surrounding the impacted left second premolar (35) which was displaced buccolingually (Figure 3). Intraoral periapical radiograph (IOPAR) revealed dilaceration of the mesial root of 36 (Figure 4).

Under local anesthesia, full thickness mucoperiosteal flap was reflected from the distal of mandibular left deciduous canine (73) to the mesial of 36 followed by extraction of the 75, 35 with surgical enucleation of the cyst and flap closure was done by using 3-0 black silk suture (Figure 5, 6, 7). The enucleated cystic mass was sent for the histopathological examination which showed stratified squamous epithelium of varying thickness with arcade like pattern and dense aggregate of chronic inflammatory cells in underlying connective tissue under $10 \mathrm{X}$ magnification confirming the diagnosis of infected dentigerous cyst (Figure 8).

Antibiotics and analgesics were prescribed and suture was removed after a week (Figure 9). Other carious teeth were restored as well.

Three months follow up showed satisfactory wound

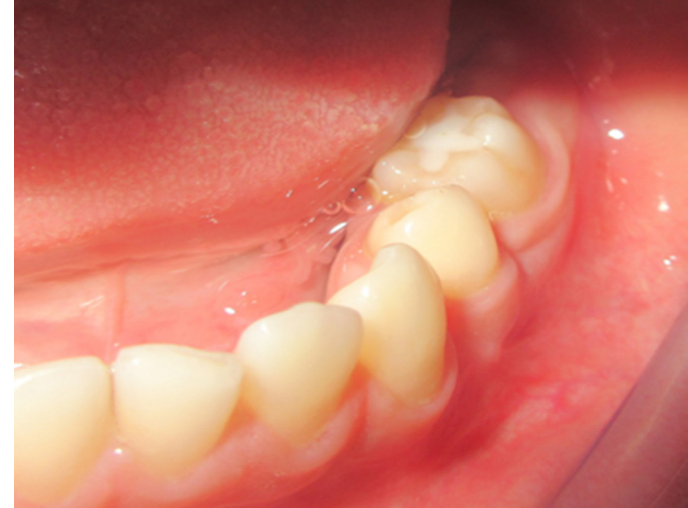

Figure 10. Three months postoperative (intraoral).

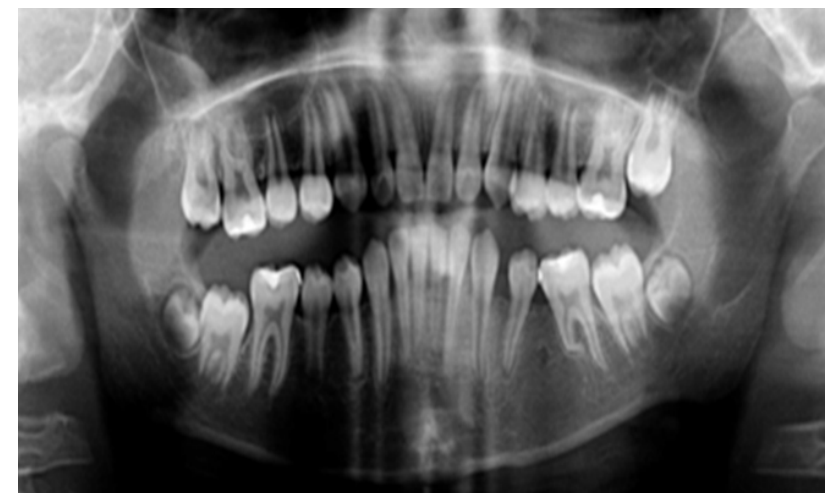

Figure 12. OPG after nine months.

healing with reduction of buccal cortical plate expansion and OPG showed marked reduction in radiolucency (Figure 10,11). Nine months, follow up OPG revealed increase in radiopacity in the space previously occupied by the cystic lesion indicating new bone formation and there was satisfactory healing with no evidence of recurrence (Figure 12).

\section{DISGUSSION}

A dentigerous cyst is one that encloses the crown of an unerupted tooth as a result of expansion of its follicle and is attached to the cementoenamel junction. ${ }^{7}$ Developmental and inflammatory are the two types of dentigerous cyst reported in the literature. ${ }^{1}$ Inflammatory type of dentigerous cyst develops from the intrafollicular spread of periapical inflammation from the overlying nonvital necrotic deciduous teeth. ${ }^{1,2}$ The present case is an inflammatory type of dentigerous cyst originated from carious deciduous second molar. Mandibular deciduous molars are more prone to caries, and its roots are more intimately associated with the follicle of its successor than any other deciduous teeth which can result in formation of inflammatory type of dentigerous cyst. ${ }^{8}$ 
Histologically, the lumen is lined with two - four layers of nonkeratinized epithelial cells. In inflammatory type there is the presence of various chronic inflammatory cells in the connective tissue. ${ }^{6}$ Although arcade like pattern of epithelium is a feature of radicular cyst, not of dentigerous cyst, this case reported even the presence of numerous chronic inflammatory cells in the connective tissue stroma suggesting the diagnosis of infected dentigerous cyst.

The treatment modalities of dentigerous cyst are either enucleation or marsupialization. Various factors like age of the patient, location of the cyst, position of tooth in relation to the cyst and root formation determine the treatment option to be chosen. ${ }^{9}$ If the cyst is associated with an unerupted tooth that is in unfavorable position for eruption then enucleation of the cyst and extraction of the offending tooth should be the treatment of choice. However, if preservation of displaced tooth is desired because the tooth is in favorable position for eruption, then marsupialization is the choice. Marsupialization, being a conservative treatment option, has lesser complications than enucleation and neighboring structures (teeth, alveolar dental nerve, floor of nose, floor of maxillary antrum) are not damaged. ${ }^{9}$ In the present case, the developing permanent mandibular left second premolar was horizontally displaced in buccolingual direction, its eruption was not possible, thus enucleation of the cyst along with extraction of the offending tooth was done.

\section{CONGLUSIONS}

Early diagnosis and treatment of dentigerous cyst is of crucial importance to prevent further complications. The unfavorable position of the impacted second premolar for eruption led to the choice for surgical enucleation and extraction of the offending tooth in our case. Fortunately, the inferior border of mandible was intact though the lesion was very close to it due to which complete enucleation of the cyst was possible rendering a favorable outcome.

Conflict of Interest: None

\section{JNAPD}

\section{REFERENGES}

1. Kirtaniya BC, Sachdev V, Singla A, Sharma AK. Marsupialization: a conservative approach for treating dentigerous cyst in children in the mixed dentition. J Indian Soc Pedod Prev Dent. 2010 Jul-Sep;28(3):203-8. [PubMed I DOI]

2. Ziccardi V.B., Eggleston T.I., Schneider R.E. Using fenestration technique to treat a large dentigerous cyst. J. Am. Dent. Assoc. 1997;128:201-5. [uㅣㄹed I DOI]

3. Yaqoob A, Wani TM, Ashraf J, Yaqoob G, Yaqub N. Conservative surgical management of a dentigerous cyst associated with an impacted mandibular canine. Dent Med Res 2014;2:49-52. [Full Text]

4. Patil S, Karpe H, Jadhav R, Kulkarni VK, Jyothi SB, Tulsani S. Erupting Permanent Second Premolar after Marsupialization of Dentigerous Cyst: Case Report. Int J Oral Health Med Res 2017;3(6):93-97. [Full Text]

5. Kapdan A, Carti Ö, Buldur B, Çukurcu Ç. Conservative Treatment of Dentigerous Cysts: Two Case Reports. J Dent Oral Biol. 2017;2(11):1071. [Full Text]

6. Mishra R, Tripathi AM, Rathore M. Dentigerous cyst associated with horizontally impacted mandibular second premolar. Int J Clin Pediatr Dent. 2014 Jan;7(1):5457. [PubMed I DOI]

7. Benn A, Altini M. Dentigerous cysts of inflammatory origin. A clinicopathologic study. Oral Surg Oral Med Oral Pathol Oral Radiol Endod. 1996 Feb;81(2):203-9. [PubMed I DOI]

8. Shibata Y, Asaumi J, Yanagi Y, Kawai N, Hisatomi M, Matsuzaki H, Konouchi H, Nagatsuka H, Kishi K. Radiographic examination of dentigerous cysts in the transitional dentition. Dentomaxillofac Radiol. 2004 Jan;33(1):17-20. [PubMed I DO]

9. Bhardwaj B, Sharma S, Chitlangia P, Agarwal P, Bhamboo A, Rastogi K. Mandibular Dentigerous Cyst in a 10-Year-Old Child. Int J Clin Pediatr Dent. 2016 JulSep;9(3):281-284. [PubMed I DOI] 